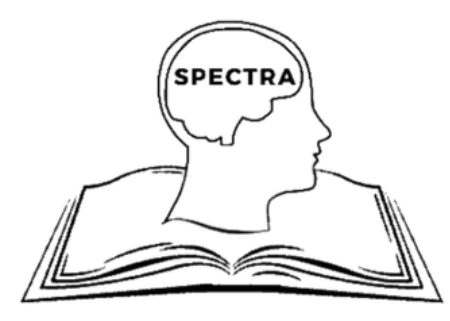

Spectra Undergraduate Research Journal

Volume 1, Issue 1

https://doi.org/10.9741/2766-7227.1005

Office of Undergraduate Research

University of Nevada, Las Vegas

digitalscholarship.unlv.edu/spectra/

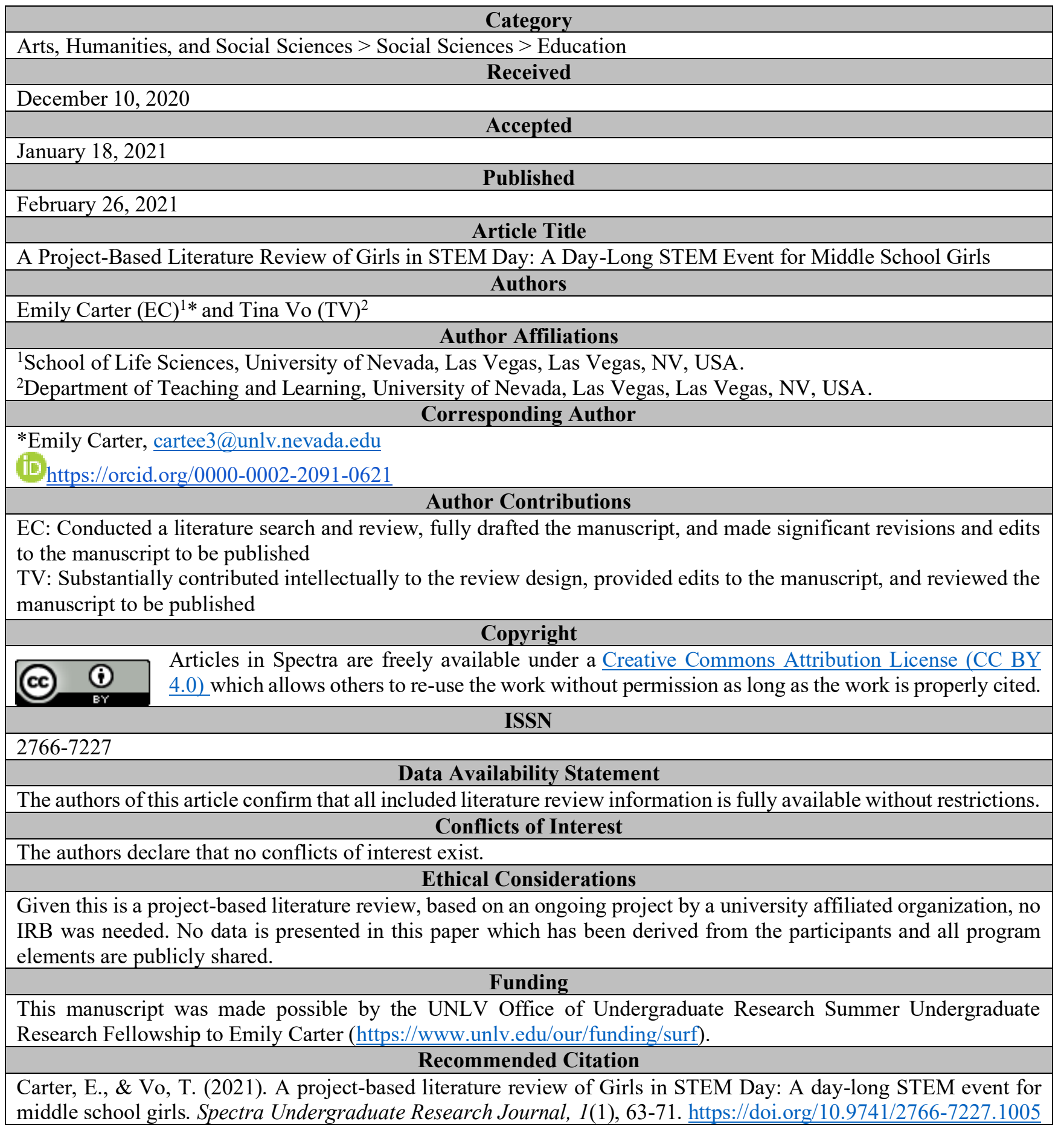




Spectra Undergraduate Research Journal
Volume 1, Issue 1, pp. 63-71
https://doi.org/10.9741/2766-7227.1005
$\begin{aligned} & \text { Office of Undergraduate Research } \\ & \text { University of Nevada, Las Vegas } \\ & \text { digitalscholarship.unlv.edu/spectra/ }\end{aligned}$

\title{
A Project-Based Literature Review of Girls in STEM Day: A Day-Long STEM Event for Middle School Girls
}

Emily Carter $^{1}$ and Tina $\mathrm{Vo}^{2}$

\section{Author Affiliations:}

${ }^{1}$ School of Life Sciences, University of Nevada, Las Vegas, Las Vegas, NV, USA

${ }^{2}$ Department of Teaching and Learning, University of Nevada, Las Vegas, Las Vegas, NV, USA

\begin{abstract}
Research specifically targeted at youth participation in STEM highlights the importance of community engagements outside of school to bolster interest in STEM. Representation of women in STEM and encouragement of girls' participation and interest in STEM fields parallels the importance of designing and implementing curriculums that enhance middle school-aged girls' participation in STEM fields. The Girls in STEM Day program hosted by UNLV Scientista Foundation is designed to encourage middle school girls of color from the Clark County School District to find interest in STEM. Interactive activities and framework analysis of the program provides prospective success towards increasing interest and participation in STEM. Evaluation of this program and activities will provide further evidence for curriculum development to triangulate girls' experiences and perceptions of STEM. The authors of this study expect to contribute specific examples indicating middle school girls' interests in STEM-based on experiences in a day-long STEM event.
\end{abstract}

Keywords: STEM education, Middle school, Girls, STEM workshops, Day-long event

The Next Generation Science Standards (National Research Council, 2013) Appendix D, emphasizes the need for all students to be supported to engage with science at all levels of education critically. Additionally, Appendix C highlights college and career readiness as a goal for science education and literacy (National Research Council, 2013). Given both of these national expectations, there are still major challenges and barriers towards science inclusion, including science education for students of color and, most prominently, representation of women of color in science fields in academia.

It is no secret that women of color are underrepresented in science, technology, engineering, and mathematics (STEM) fields. Historically representation of women in science has been an uphill challenge in the past century. Rosalind Franklin, a scientist who contributed to the discovery of the DNA double helix structure; Lise Meitner, contributing scientist to discovering nuclear fission, and Ada Lovelace, development of modern computer programing, are among many other female scientists who have been at the forefront of lack of representation, acknowledgment, and recognition in science fields for major contributions used today (Gupta, 2020). Although changes in today's society have enabled more opportunities for women to participate in STEM fields, underrepresented minorities experience the greatest gap among women in STEM. Today there is growing evidence that underrepresentation of women from minority backgrounds is not a matter of academic achievement 
but personal identity based on personal perception, goals, and perceived understanding of a man's advantage in STEM fields (Kang et al., 2019).

Often referred to as a 'leaky pipeline,' this metaphor conveys that women and minorities are filtered out of STEM fields and has been the focus of study for the past decades. While some research indicates areas of this pipeline might be improving within higher education (Miller \& Wai, 2015), a larger narrative outlines there is work to be accomplished across all levels of education (Clark Blickenstaff, 2005). Research specifically targeted at youth participation in STEM highlights the importance of community engagements outside of school to bolster interest and support learning within and across STEM areas (Lyon et al., 2012). An analysis of girls' perceptions and interest in STEM-based on participation in STEM events provides the opportunity to better understand, articulate, and encourage girls to pursue STEM learning.

The Girls in STEM Day program, hosted by the UNLV Scientista Foundation, was created to address the gap between youth and girls' participation in science learning and STEM. This paper is a projectbased literature review of the Girls in STEM Day program.

\section{Girls in STEM Day Program:}

\section{Figure 1.}

UNLV Scientista Foundation members during the opening session of Girls in STEM Day 2020

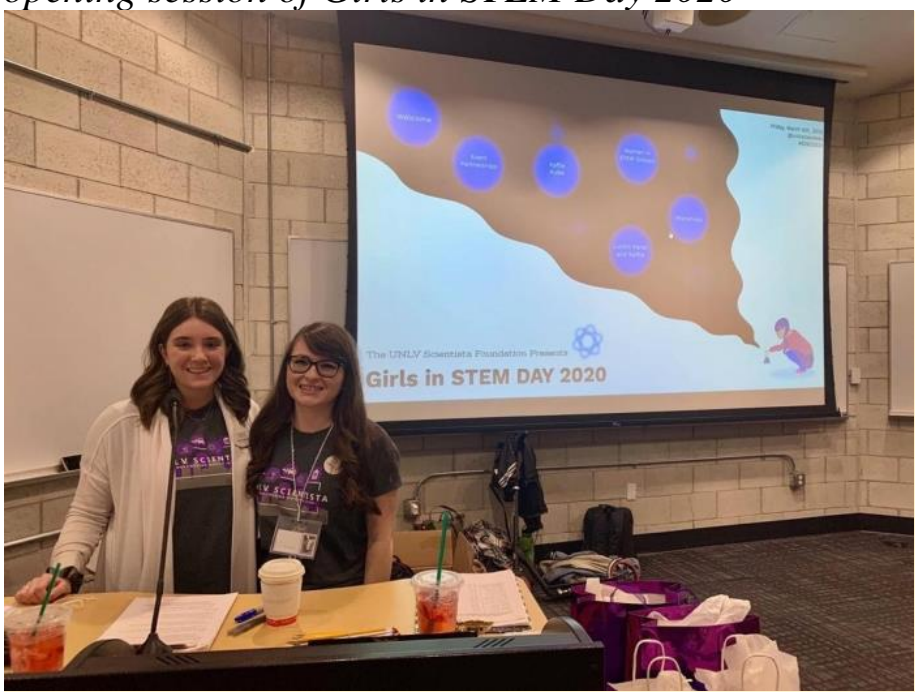

Figure 2.

Girls in STEM Day 2020 participants and UNLV

Scientista Foundation

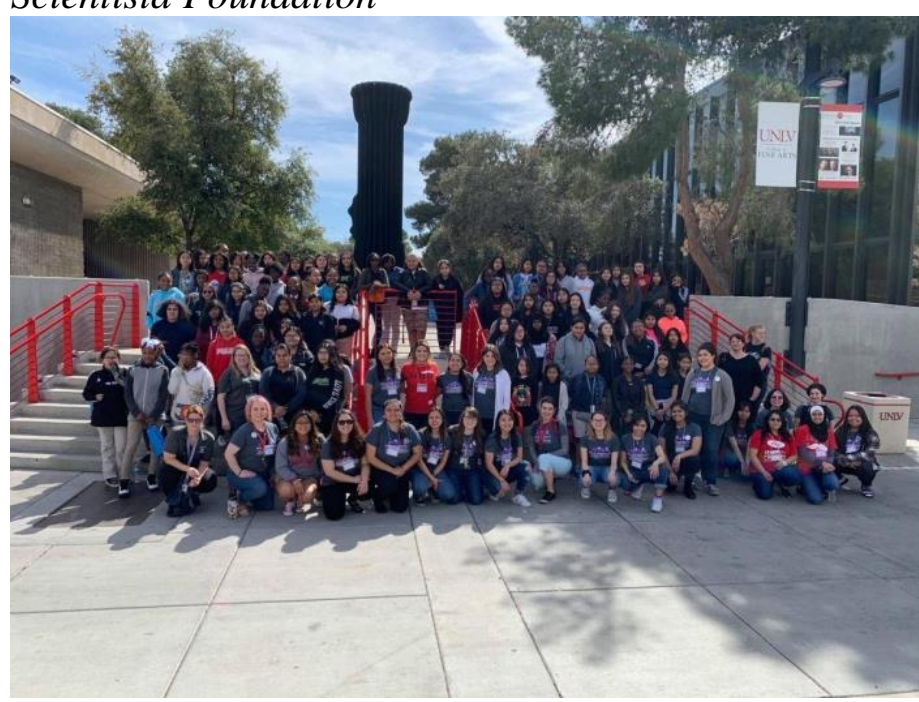

Girls in STEM Day is a day-long event of STEM-based workshops for middle school-aged girls from minority populations. Girls in STEM Day is hosted by the UNLV Scientista Foundation, a registered student organization at UNLV (Figure 1 and 2). The inspiration for Girls in STEM Day comes from the national Scientista Foundation's mission to empower pre-professional women in science, technology, engineering, and math (STEM) (Scientista Foundation, 2020). Scientista Foundation connects women across campuses to empower women in STEM through one voice of action, advancing women in sciences.

With the evidence that women are underrepresented in STEM fields, the UNLV Scientista Foundation developed Girls in STEM Day to inspire young minority women to find interest and pursue interests in STEM at a young age, instituting the support of developing programs and opportunities for women in STEM.

This program pulled from a large urban school district. The district indicates student minority enrollment to be $76 \%$ (primarily Hispanic; Public School Review, 2020). Furthermore, there are 59 Title 1 middle schools in the district, representative of the large majority-minority student population based on ethnicity in urban areas $(2019,2018-2019$ Title 1 Schools). 
Annually, the student club division of Scientista Foundation at UNLV brings together women pursuing STEM careers to host Girls in STEM Day for 100 middle school-aged girls in minority populations from throughout the Las Vegas valley. The goal of
Girls in STEM Day is to inspire young girls in minority populations to find interest in STEM fields through interactive workshops and activities as well as mentorship from college women pursuing STEM careers.

\section{Girls in STEM Day Program Layout:}

\section{Figure 3.}

Girls in STEM Day program flowchart

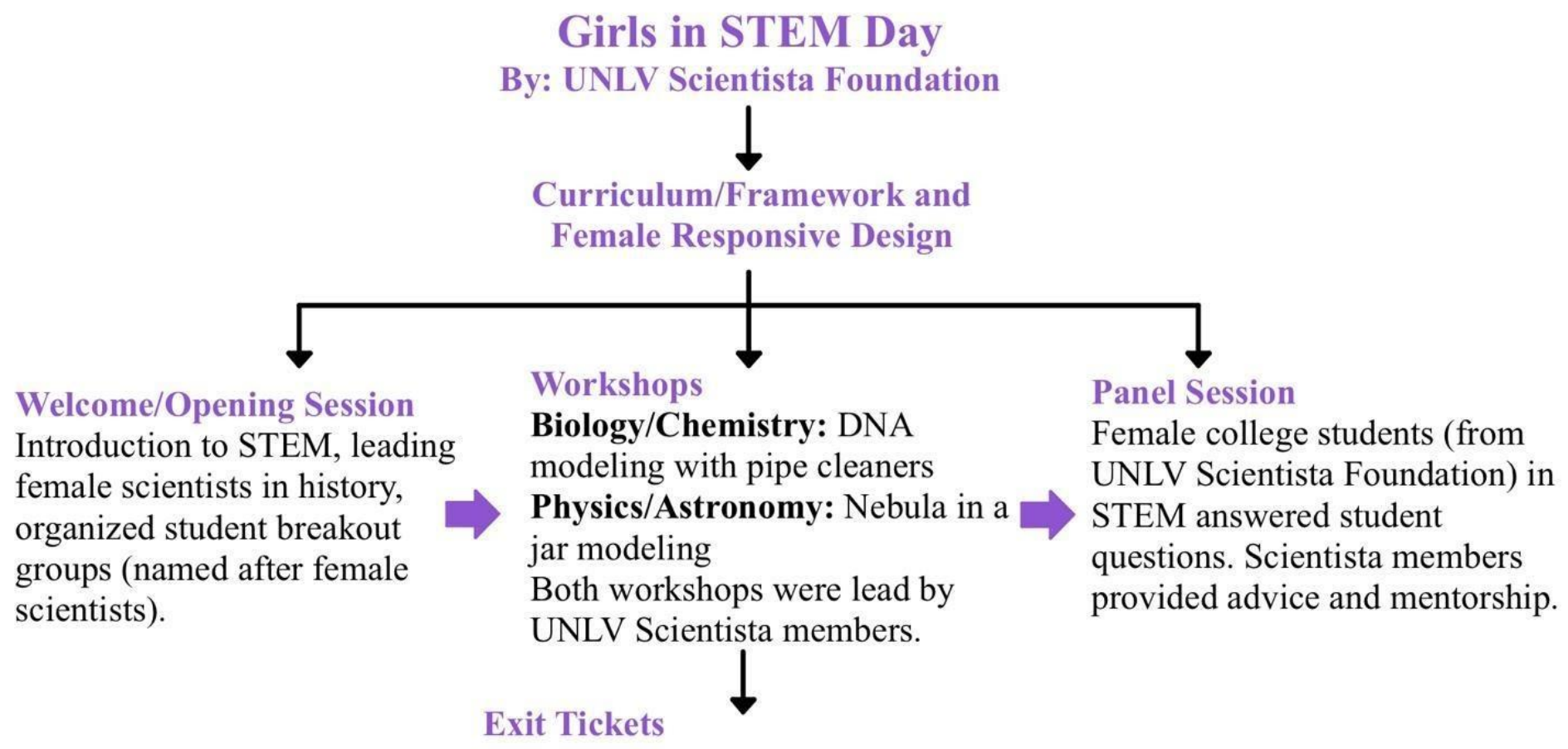

\section{Assessing STEM interest:}

Free response questions to assess student engagement and experience. Conducted in the last five minutes of the workshop.

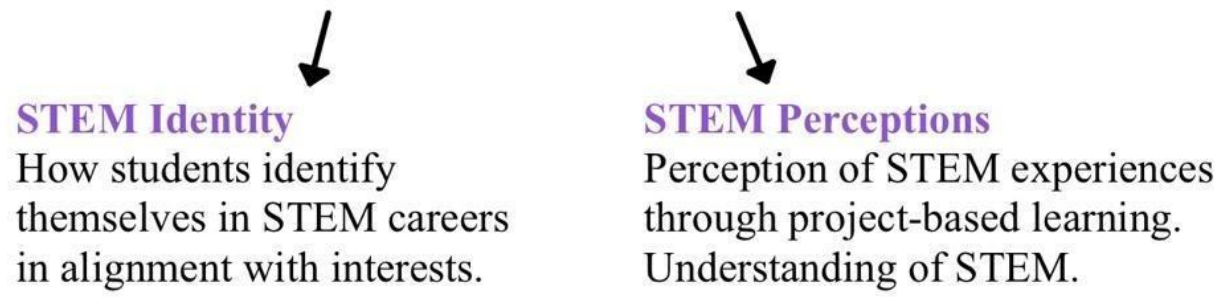

Girls in STEM Day consists of a full day on the university campus (Figure 3). Students participate in a welcome session where they are introduced to the different STEM fields, including biology/chemistry, physics/astronomy, computer science, and mathematics. The opening session's main goal and impact was to introduce attendees to leading female scientists in a variety of STEM fields and randomly assign students into groups named after female scientists. Every Girls in STEM Day, different female scientists are chosen. For this day, students were organized in the Emmy Noether, Farida Bedwei, Valerie Thomas, or Alice Ball group. These women are among history's leading female scientists in STEM 
fields, including math, computer science, astronomy, and chemistry. The opening session's goal was to develop female role model images representative of the girls attending the day.

Following the opening session, participants attended two workshops including a biology/chemistry themed workshop and a physics/astronomy themed workshop. The workshops were designed to include a female responsive approach that removes the traditional masculinized environment in which STEM is taught and directed (Dancstep \& Sindorf, 2018).

The biology/chemistry workshop hands-on activity was building a DNA model using pipe cleaners derived from the National Science Teaching Association, Idea Bank (National Science Teaching Association, 2004). Students learned the four primary DNA nucleotide bases and the DNA helix structure. DNA models were built using low-cost materials (e.g., pipe cleaners, tape, children's scissors). Student volunteers from the UNLV Scientista Foundation hosted and instructed students on how to participate in the hands-on activity. For the physics/astronomy workshop, students were taught about nebulas in space. Nebulas are formed as a giant cloud of dust and gas in space, presented in many different naturally occurring colors (Doyle, 2019). Students crafted nebulas in a jar using low-cost materials: glue, glitter, food coloring, cotton balls, water, and plastic jars with a lid (Public Broadcasting Service, 2020). Student volunteers from Scientista Foundation in physics and relevant majors hosted this workshop and taught students about nebulas and the hands-on learning activity. During the workshop, students were also introduced to female scientists in the respective science fields, and college students served as mentors and answered questions about school, challenges and real-life situations women in science pursue daily.

The use of exit tickets is a unique way to assess student interest and knowledge following an activity or similar workshop period. Often structured as a freeresponse assessment, exit tickets elicit students' thinking with individualized feedback and identify learning based on short specific prompts answered in five minutes (Black \& Wiliam, 1998). An analysis of student responses on exit tickets further provides opportunities for evaluation of the workshop activity and helps to identify patterns in learning gaps or ideas students express (Fowler et al., 2019). The use of exit tickets in a STEM program for middle school and high school students identified student perceptions of the assignment given and differences in student perception of experience from the activity (Lytle et al., 2019). Exit tickets provide the opportunity to gather information about the experience and learning perceptions of students participating in STEM activities.

Students were given one three by five blank notecard in the last five minutes of each workshop and were instructed to answer pre-planned multiple choice and free response questions written on a whiteboard by a Scientista Foundation member. The following questions were used for the two respective workshops. Students were asked to (1) rate their enjoyment of the workshop and (2) explain their ranking. Next, students were asked about (3) what they learned from the activity, (4) questions they still have, and (5) if the workshop increased their interest in biology and chemistry, explaining why or why not. An identical format was provided for both the biology and chemistry, then physics and astronomy workshops. Student rankings of enjoyment of the workshop were indicated as A (I did not like it), B (I liked it a little), to $\mathrm{C}$ (I liked it a lot). Completion of the questions on the notecards enabled students to leave the workshop and progress to other Girls in STEM Day activities.

Following workshop activities and rotations between the student groups named after female scientists, students attended a meal and panel session where female college students in STEM, led by the campus Scientista Foundation club, enabled the middle school girls to ask challenging and thought-provoking questions in learning about the college student life for women pursuing STEM. The panel closed the Girls in STEM Day event.

This STEM day layout provides opportunities for growth and change. The following section presents background literature to improve pieces of the Girls in STEM Day program. Emphasis is placed on the handson activity workshops conducted during the program.

\section{Literature Review of Girls in STEM Day Components: \\ STEM Experiences \\ Often middle school girls have limited exposure to STEM subjects and understanding of}


STEM disciplines through traditional classroom instruction (Guzey et al., 2014). Wieselmann et al. (2020) identified that students' prior experiences with mathematics in school-based classrooms often results in fewer positive dispositions towards mathematics and STEM fields. Integrating a new curriculum after school with project-based learning experiences in mathematics and STEM fields has been shown to stimulate interest in STEM.

Curriculum and Framework

Designing a curriculum effective for STEM learning includes integrating content learning among all STEM fields in activities and, furthermore, using a variety of contexts applying real-world examples to make learning more valuable (Moore et al., 2014). Strategic implementation of a STEM-based curriculum that proves to be impactful and valuable for learning has been emphasized in various formats, including hands-on activities, workshops, day-long or weeklong events, and even identifying STEM in the industry through field trips. These formats for STEM learning are found to typically involve out-of-school learning opportunities (Baren et al., 2019). Conceptual frameworks for a STEM education program include target student population groups such as age, grade level, and further, gender and ethnicity. Most day-long STEM events will focus on a specific STEM topic or category, such as engineering principles and learning (Cunningham et al., 2020).

Several STEM activities and events have been implemented to enhance girls' interests and learning of STEM fields. Craig \& Horton (2009) developed a program called Gr8 Designs for Gr8 Girls implemented for middle school-aged girls for three days to encourage interest and impact learning computer science. Other programs included off-campus camps exploring physics research in high magnetic fields with touring, hands-on activities, and challenges to develop girls' participation in STEM in an industry setting (Hughes et al., 2013). Project-based learning curriculum activities implemented the hands-on components of a variety of programs illustrated in teaching science (Harris et al., 2015). A collaboration of different program designs further complicates challenges to appeal to girls responsively, enhancing action and engagement in STEM learning activities.

Female Responsive Design
Designing a low-pressure environment and female-responsive STEM learning activities enhances young girls' interest in STEM fields and science overall (Dancstep et al., 2018). Through the use of unique science project workshops in a casual setting, middle school girls find the great opportunity to explore scientific questions, articulate personal identity in the science experience, and recognize their interest in STEM. Creating an informal learning environment provided minority middle and high school girls the opportunity to showcase their personalities and openly define their career vision and overall perceptions of STEM (McCreedy et al., 2013). Enabling students to pursue STEM identity and develop perceptions is the premise of several studies, including our day-long STEM event for middle school-aged girls of color.

STEM Identity and Perceptions

The role of identity in STEM research among underrepresented minorities is increasingly important in understanding young girls' interests and inspiration in pursuing STEM careers (King \& Pringle, 2019). Recent United States initiatives to expand STEM educational opportunities for ethnic minorities, women and girls have further identified the same evidence indicating a personal identity and perception of science disconnect in interest in STEM fields (Tan et al., 2013). It is increasingly important to understand and address the identity gap in young girls' perception and interests in STEM to preserve a future of equal representation of women in STEM fields, resolving the current 'leaky pipeline.'

Literature presents that one of the most common perceptions girls have about STEM fields and careers is that there are more advantages for boys pursuing STEM careers in achieving success than girls pursuing STEM careers (Wieselmann et al., 2020). Additionally, STEM careers are expensive to pursue with challenging classes (Kang et al., 2019). The perceptions present common challenges preventing minority girls from pursuing STEM careers further complicated by lack of opportunity to afford and attend afterschool STEM programs. Positive correlations among girls-only STEM programs and perceptions of STEM learning experiences indicate further value of STEM programs designed for girls (McCreedy \& Dierking, 2013). 


\section{STEM Interests and Assessing}

STEM interests are categorized in a variety of ways. Day-long STEM programs are prevalently based around one STEM area of interest, such as chemistry sciences versus engineering sciences. Students who attend these programs that focus on one area of STEM have previously identified common interest in the field of choice. Prieto-Rodriguez et al. (2020) identified the majority of studies in their systematic review of secondary school interventions for girls in STEM were career choice based, focusing on one area of STEM, in which the students participating in the program had previously identified interest in the STEM content area. Among the STEM programs focused on one area of science learning, mentorship with older students in STEM or women in science fields is common. One STEM program focused on the value of online mentorship for young secondary girls in STEM (Stoeger et al., 2019). Mentorship quality and relationships through STEM learning programs have shown to improve girls' interests and participation in STEM. The Girls in STEM Day program did not focus on a specific area of STEM, but pursued the goal of introducing middle school-aged girls to all areas of STEM, considering students from the program population may not have had exposure to science or STEM learning principles previously. Mentorship in STEM interests was briefly included in the Girls in STEM Day program, in which female college students in STEM from a variety of major disciplines provided opportunities for students to engage and ask questions. Identifying girls' interest in STEM among STEM days or camp events intersects with perceptions and identity. Craig et al. (2009) performed pre- posttests assessments of interest in different types of STEM versus non-STEM careers, emphasizing computer science designed into the program. The use of pre- and post-tests assessments of STEM interest is common among open free-response answer questions. Hughes et al. (2013) identified student interest in STEM in preversus post-test surveys assessing girls' favorite subject in school, least favorite subject in school, and career interest. Interviews were also used to review and assess interest in STEM following the STEM program. The methodology used to assess young girls' or middle school girls' interests in STEM commonly correlates with students' interests before and after a STEM event, in addition to assessing why interest had increased or decreased. Methodology for assessing interest is applied as a combination from among past research examples.

\section{Conclusion}

Evidence of the 'leaky pipeline' among higher education for women in STEM emphasizes the large need to support youth and girls' participation in STEM education (Prieto-Rodriguez et al., 2020). Initiatives such as Girls in STEM Day through UNLV and several supporting organizations provide opportunities for young girls to experience STEM learning outside of traditional classroom environments, often for the first time in their educational path. A critically evaluated and planned out-of-school STEM day framework provides a valuable opportunity for an implemented program to positively impact middle school-aged girls from minority populations in education and STEM. Changing girls' perceptions of STEM from negative to positive based on experiences challenges the 'leaky pipeline' identified in higher education levels. Greater national initiatives and support for women in STEM parallels the need for STEM identity and leveling the playing field for girls to feel confident and supported in pursuing science careers (Watermeyer, 2012). These present the starting point among local and national initiatives for girls' and women's STEM participation.

\section{Discussion and Future Directions}

A full evaluation of this program in addition to analyses exploring the hands-on activities and girls' evaluated interest in STEM will provide further evidence impactful for developing a curriculum that brings more girls to develop positive perceptions in pursuing STEM careers. The overarching goals of the implementation of this program by UNLV Scientista is to serve a local community and work to lessen, if not eliminate, the barriers that prevent girls and women from pursuing STEM fields confidently.

Developing an enhanced curriculum framework for Girls in STEM Day would involve integrating greater educational hands-on activities and workshops that have been proven to impact STEM learning and content retention of middle school-aged students (Harris et al., 2015). Furthermore, allowing the opportunity for girls participating in the program to 
pursue one STEM area of interest following introduction to all STEM categories could apply and leverage student perception of different fields of STEM and enhance positive perceptions of STEM.

Another area of focus in the curriculum framework of the program includes lengthening the program beyond one day. Girls in STEM Day 2020 was limited by the travel restrictions issued by the school district the target population of students were pulled from. As a result, the day was cut in half, ending after lunch. This edit to the Girls in STEM Day program greatly limited learning opportunities and collaborations among mentorship and STEM interest enhancement. Provided greater financial support from the university and outside collaborations, lengthening the STEM program to a few days or even a week would provide students with an immersed experience of learning a variety of STEM categories as indicated by various STEM programs analyzed in this review. Future possibilities to investigate include hosting the program more than once a year. Hosting the program on a semester basis could enhance student engagement and popularity of the program, greater opportunities to evaluate the program, and more program support on educational platforms.

Elements of a female responsive design provide new insight into designing programs applicable for student engagement. Research on female responsive design and effectiveness is minimal and was implemented in the Girls in STEM Day program in minor additions to the set up with learning materials distributed. Analyzing the impact of female responsive design versus traditional design among project-based learning opportunities provides future directions to enhance educational approaches (Dancstep \& Sindorf, 2018).

The overall assessment of STEM interest in the Girls in STEM Day program was limited to the availability of assessment resources, in addition to time constraints. Integrating pre- and post-test assessments along with individual workshop exit tickets as used in the program already will indicate further points where the program can be designed for effectiveness. As implemented by Baran et al. (2018), student interviews include student attitude assessment used to triangulate data analyzing student perception and interest in STEM.
Given greater resources, time, and commitment to improving the Girls in STEM Day program, UNLV Scientista Foundation can use the information gathered here to innovate the program while addressing the gender gap of representation of women in STEM.

\section{Importance to the Field}

Research focused on supporting girls and young women within STEM fields should be a priority within science education ( $\underline{N R C, 2013)}$ as opportunity gaps and systematic barriers exist hindering equity within and across scientific fields. Much work has been done exploring and bolstering ideas around girl's engagement with science. This work adds to that conversation and also contributes to the larger literature review community by providing an analysis of important characteristics in the development and implementation of a STEM event that measures engagement and interest in STEM. This is important for scientists looking to engage specific populations of underrepresented students and informal educators looking to provide science opportunities for young girls.

\section{Acknowledgements}

The Scientista Foundation for creating an excellent program [Girls in STEM Day] helping to grow the next generation of strong women scientists and engineers. The Office of Undergraduate Research for providing support for undergraduate researchers among funding, presenting and publishing opportunities.

\section{References}

Baran, E., Canbazoglu Bilici, S., Mesutoglu, C., \& Ocak, C. (2019). The impact of an out-ofschool STEM education program on students' attitudes toward STEM and STEM careers. School Science and Mathematics, 119(4), 223-235.

Black, P., \& Wiliam, D. (2005). Inside the black box: Raising standards through classroom assessment. Granada Learning. Clark Blickenstaff*, J. (2005). Women and science careers: leaky pipeline or gender filter?. Gender and education, 17(4), 369-386. 
Clark County School District. (2019). 2018-2019

Title 1 Schools. Clark County

School District College, Career, and Equity

Unit. https://aarsi.ccsd.net/title-i/school-basedsupport/title i-schools/2018-2019/.

Craig, M., \& Horton, D. (2009, March). Gr8 designs for Gr8 girls: a middle-school program and its evaluation. In Proceedings of the 40th ACM technical symposium on Computer science education (pp. 221-225).

Cunningham, C. M., Lachapelle, C. P., Brennan, R. T., Kelly, G. J., Tunis, C. S. A., \& Gentry, C. A. (2020). The impact of engineering curriculum design principles on elementary students' engineering and science learning. Journal of Research in Science Teaching, 57(3), 423-453.

Dancstep, T., \& Sindorf, L. (2018). Creating a Female-Responsive Design Framework for STEM exhibits. Curator: The Museum Journal, 61(3), 469-484.

Doyle, H. (2019, June 28). What is a Nebula? National Aeronautics and Space Administration. https://spaceplace.nasa.gov/nebula/en/.

Fowler, K., Windschitl, M., \& Richards, J. (2019). Exit Tickets. The Science Teacher, 86(8), 1826.

Gupta, D. (2020, August 29). Five Discoveries Made By Women That Were Credited to Men. She the People: The Women's Council. https://www.shethepeople.tv/home-topvideo/five-discoveries-made-by-women-thatwere-credited-to-men/.

Guzey, S.S., Harwell, M. and Moore, T. (2014), Attitudes toward STEM. Sch Sci Math, 114: 271-279. doi:10.1111/ssm.12077.

Harris, C. J., Penuel, W. R., D'Angelo, C. M., DeBarger, A. H., Gallagher, L. P., Kennedy, C. A., \& Krajcik, J. S. (2015). Impact of project-based curriculum materials on student learning in science: Results of a randomized controlled trial. Journal of Research in Science Teaching, 52(10), 1362-1385.

Hughes, R. M., Nzekwe, B., \& Molyneaux, K. J. (2013). The single sex debate for girls in science: A comparison between two informal science programs on middle school students' STEM identity formation. Research in Science Education, 43(5), 1979-2007.

Kang, H., Calabrese Barton, A., Tan, E., D Simpkins, S., Rhee, H. Y., \& Turner, C. (2019). How do middle school girls of color develop STEM identities? Middle school girls' participation in science activities and identification with STEM careers. Science Education, 103(2), 418-439.

King, N. S., \& Pringle, R. M. (2019). Black girls speak STEM: Counterstories of informal and formal learning experiences. Journal of Research in Science Teaching, 56(5), 539-569. https://doi.org/10.1002/tea.21513

Lyon, G. H., Jafri, J., \& St Louis, K. (2012). Beyond the Pipeline: STEM Pathways for Youth Development. Afterschool Matters, 16, 48-57.

Lytle, N., Cateté, V., Boulden, D., Dong, Y., Houchins, J., Milliken, A., Isvik, A., Bounajim, D., Wiebe, E., Barnes, T., (2019). Use, Modify, Create. 395-401. https://doi.org/10.1145/3304221.3319786.

McCreedy, D., \& Dierking, L. D. (2013). Cascading influences: Long-term impacts of informal STEM experiences for girls. The Franklin Institute.

https://www.fi.edu/sites/default/files/cascadin g-influences.pdf.

Miller, D. I., \& Wai, J. (2015). The bachelor's to Ph.D. STEM pipeline no longer leaks more women than men: A 30-year analysis. Frontiers in psychology, 6, 37.

Moore, T. J., Stohlmann, M. S., Wang, H. H., Tank, K. M., Glancy, A. W., \& Roehrig, G. H. (2014). Implementation and integration of engineering in K-12 STEM education. In Engineering in pre-college settings: Synthesizing research, policy, and practices (pp. 35-60). Purdue University Press.

National Research Council. (2013). Next Generation Science Standards: For States, By States. Washington, DC: The National Academies Press. https://doi.org/10.17226/18290. 
National Science Teaching Association. (2004). Idea Bank: Pipe Cleaner DNA.

https://www.nsta.org/resources/idea-bankpipe-cleaner-dna.

Prieto-Rodriguez, E., Sincock, K., \& Blackmore, K. (2020). STEM initiatives matter: results from a systematic review of secondary school interventions for girls. International Journal of Science Education, 1-18.

Public Broadcasting Service. (n.d.). Make a Galaxy in a Jar. PBS for Parents. Retrieved November 9, 2020, from https://www.pbs.org/parents/crafts-andexperiments/make-a-galaxy-in-a-jar.

Public School Review. (n.d.). Clark County School District Public School Review. Retrieved August 27, 2020, from https:/www.publicschoolreview.com/nevada/ clark-county-school-district/3200060-schooldistrict/middle.

Scientista Foundation. (n.d.). About Scientista. Scientista Foundation, Community for Women In STEM. Retrieved August 27, 2020 , from http://www.scientistafoundation.com/abo ut- us.html.

Stoeger, H., Debatin, T., Heilemann, M., \& Ziegler, A. (2019). Online Mentoring for Talented Girls in STEM: The Role of Relationship Quality and Changes in Learning Environments in Explaining Mentoring Success. New directions for child and adolescent development, 2019(168), 75-99.

Tan, E., Calabrese Barton, A., Kang, H., \& O'Neill, T. (2013). Desiring a career in STEMrelated fields: How middle school girls articulate and negotiate identities-in-practice in science. Journal of Research in Science Teaching, 50(10), 1143-1179.

University of Nevada, Las Vegas. (2020). UNLV

Designated AANAPISI, HSI, and MSI Institution. UNLV Designated AANAPISI, HSI, and MSI Institution. https://www.unlv.edu/diversityinitiatives/msi\# : : text=UNLV\%20Designated\%20AANAPISI
$\% 2 \mathrm{C} \% 20 \mathrm{HSI} \% 2 \mathrm{C} \% 20$ and,Minority\%20Servi ng\%20Institution\%20(MSI).

Watermeyer, R. (2012). Confirming the legitimacy of female participation in science, technology, engineering and mathematics (STEM): evaluation of a UK STEM initiative for girls. British Journal of Sociology of Education, 33(5), 679-700.

Wieselmann, J. R., Roehrig, G. H., \& Kim, J. N. (2020). Who succeeds in STEM?

Elementary girls' attitudes and beliefs about self and STEM. School Science and Mathematics, 120(5), 297-308. 